\title{
TRABALHO E EDUCAÇÃO NA REPRODUÇÃO SOCIAL DO HOMEM
}

\section{TRABAJO Y LA EDUCACIÓN EN LA REPRODUCCIÓN SOCIAL DEL HOMBRE}

\section{WORK AND EDUCATION IN SOCIAL REPRODUCTION OF MAN}

DOI: http://dx.doi.org/10.9771/gmed.v11i1.25615

Vanderlei Amboni ${ }^{1}$

\begin{abstract}
Resumo: O artigo trata do trabalho e da educação como base ontológica do homem e seu processo de reprodução social. Partimos do trabalho como princípio da vida humana, que nasce em meio à luta pela existência da vida, mas traz a educação como polo de reprodução social mediado pelo trabalho. O estudo situa trabalho e educação como expressão do homem, que necessita (re)produzir sua vida, pois comer, beber, vestir e morar se conquista no domínio da natureza. Para esse fim, o estudo e análise do objeto trabalho e educação tem como referência autores marxistas, onde buscar-se-á destacar as posições teóricas dos mesmos sobre a base material que funda o ser social, mas aprofundamos o estudo do ser social sob o capitalismo.
\end{abstract}

Palavras-chave: Trabalho; Educação; Ser Social; Reprodução Social; Capitalismo.

Resumen: El artículo trata del trabajo y de la educación como base ontológica del hombre y su proceso de reproducción social. Partimos del trabajo como principio de la vida humana, que nace en medio de la lucha por la existencia de la vida, pero trae la educación como un polo de reproducción social mediado por el trabajo. El estudio sitúa trabajo y educación como expresión del hombre, que necesita (re) producir su vida, pues comer, beber, vestir y vivir se conquista en el dominio de la naturaleza. Para este fin, el estudio y análisis del objeto trabajo y educación tiene como referencia autores marxistas, donde se buscará destacar las posiciones teóricas de los mismos sobre la base material que funda el ser social, pero profundizamos el estudio del ser social bajo el capitalismo.

Palabras clave: Trabajo. Educación. Sea Social. La reproducción social. Capitalismo.

Abstrac: The article deals with work and education as the ontological basis of man and his process of social reproduction. We start from work as a principle of human life, born in the struggle for the existence of life, but brings education as a pole of social reproduction mediated by work. The study situates work and education as an expression of the man who needs to (re) produce his life, since eating, drinking, dressing and living is achieved in the realm of nature. For this purpose, the study and analysis of the work object and education is based on Marxist authors, where it will be sought to highlight the theoretical positions of the same on the material basis that founds the social being, but deepen the study of the social being under the capitalism.

Keywords: Work. Education. Be Social. Social reproduction. Capitalism.

\section{Introdução}

O artigo analisa trabalho e educação na perspectiva ontológica do homem, tendo como pressuposto a concepção marxista de trabalho e educação expondo algumas articulações de Marx e Engels e de autores marxistas como Lukács, Frigotto, Saviani etc, como fundamento às discussões sobre trabalho e educação na (re)produção social do homem.

A problemática do estudo situa trabalho e educação como expressão do ser social materializado em homem que necessita reproduzir sua condição social de homem, pois como ser vivo necessita comer, beber, vestir-se, ter moradia etc, e isto se conquista pela transformação da natureza na criação de produtos 
com valor de uso. Para esse fim, o estudo e análise do objeto trabalho e educação buscar-se-á destacar as posições teóricas dos referidos autores sobre a base material que funda o ser social, mas aprofundamos o estudo do ser social sob o capitalismo. É sobre esta temática que o presente trabalho tratará.

\section{Trabalho e educação na materialidade do homem}

$$
\begin{aligned}
& \text { O potencial do homem, para Marx, é um potencial dado; o homem é, por assim dizer, a } \\
& \text { matéria-prima humana que, como tal, não pode ser modificada, tal como a estrutura do } \\
& \text { cérebro tem permanecido a mesma desde a aurora da história. Contundo, o homem de } \\
& \text { fato muda no decurso da história: êle se desenvolve, se transforma, é o produto da } \\
& \text { história; assim como êle faz a história, êle é seu próprio produto. A história é a história da } \\
& \text { auto-realização do homem; ela nada mais é que a autocriação do homem por intermédio } \\
& \text { de seu próprio trabalho e produção: 'o conjunto daquilo a que se denomina história do } \\
& \text { mundo não passa de criação do homem pelo trabalho humano, e o aparecimento da } \\
& \text { natureza para o homem; por conseguinte, êle tem a prova evidente e irrefutável de sua } \\
& \text { autocriação, de suas próprias origens' (FROMM, 1962, 35-36). }
\end{aligned}
$$

Ao produzir a vida material o homem se afasta da barreira natural pelo trabalho. Por sua natureza, produz uma determinada forma de educação como meio de reprodução social. Este processo se materializa socialmente tendo no ato educacional um princípio do trabalho. Sua forma é determinada pela ação do homem na formação social, cujo alicerce enquadra o sujeito às determinações sociais, pois o mesmo não pode escolher seu local de nascimento, nem mesmo sua condição histórico-social. O trabalho, portanto, é sujeito constitutivo do homem e, por meio dele, assegura a reprodução da natureza humana, via sociedade. Dessa forma, Paro sustenta que "o trabalho em sua forma humana é, [...] a mediação que o homem necessita para construir-se historicamente" (PARO, 1999, 106). Por isso, Saviani assevera que o trabalho educativo é um "ato de produzir, direta e intencionalmente, em cada indivíduo singular, a humanidade que é produzida histórica e coletivamente pelo conjunto dos homens", pois “o objeto da educação diz respeito, de um lado, à identificação dos elementos culturais que precisam ser assimilados pelos indivíduos da espécie humana para que eles se tornem humanos e, [...] e concomitantemente, à descoberta das formas mais adequadas para atingir esse objetivo" (SAVIANI, 2003, p. 13). Complementando esta relação trabalho-educação, Frigotto assevera que o "princípio educativo do trabalho" "deriva de sua especificidade de ser uma atividade necessária, desde sempre, a todos os seres humanos", posto que "o trabalho constitui-se, por ser um elemento criador da vida humana, num dever e num direito". Dessa forma, "um dever a ser aprendido, socializado, desde a infância", pois "trata-se de aprender que o ser humano - como ser natural - necessita elaborar a natureza, transformá-la, e pelo trabalho extrair dela bens úteis para satisfazer suas necessidades vitais e socioculturais" (FRIGOTTO, 2010, p. 20) e, com isto, reproduzir-se biológica e socialmente.

Dessa forma, Saviani (2015) sustenta que o homem cria o mundo humano a partir do trabalho, pois produz a natureza humana sobre a base da natureza biofísica, mas o cria por meio do trabalho e, com ele, as diversas formações sociais, sob a qual o indivíduo não possui controle. $\mathrm{O}$ trabalho cria o mundo humano, mas o acesso ao mundo, à realidade, é um processo mental, que exige do homem a criação conceitual do real, pois o real se manifesta ao ser social como representação de si mesmo, portanto, como real abstrato. Este processo não é novo. Sua existência nos remete aos primórdios da vida do homem na terra. De quanto o verbo se fez carne e se materializou no homem social por meio do trabalho, ou seja, 
aquilo que Marx chamou de "afastamento da barreira natural". Por isso, o trabalho "e, por excelência, a forma mediante a qual o homem produz suas condições de existência, a história, o mundo propriamente humano, ou seja, o próprio homem" (FRIGOTTO, 1995, p. 31) e, com ele, também, as sociedades e suas formas de educação, que são históricas. Isto ocorre porque o "trabalho tornou possível ao homem superar suas fraquezas e limitações frente aos outros animais e frente a natureza. O homem pode enfim se defender, morar, se alimentar melhor, etc" (ALVES; RODRIGUES, 2015, p. 62). No domínio da natureza o homem cria forças sociais que denominamos de política, como ato de regulamentar sua própria vida e os torna cativo desde ato, que todos se submetem.

Pensar o trabalho, portanto, é refletir sobre o sentido expresso por Marx na A Ideologia Alemã, quando escreveu que há duas ciências, a ciência da história e a ciência da natureza. No princípio da vida havia a química, a biofísica etc, mas como ciências da natureza, pois elas agiam sobre o mundo orgânico sem a interferência do homem. A ciência da história é a ciência do homem real, hominizado e humanizado pelo trabalho, cuja premissa elencada por Marx e Engels para a história do homem "é, naturalmente, a existência de indivíduos humanos vivos primeiro. O primeiro fato a constatar é, pois, a organização corporal desses indivíduos e, por meio dela, sua relação dada com o restante da natureza", pois "são os indivíduos reais, sua ação e suas condições materiais de vida, tanto aquelas por eles já encontradas como as produzidas por sua própria ação" (MARX; ENGELS, 2007, p. 86-87) que determinam o tipo de homem e de sociedade a construir e a reproduzir. Com isso, inferimos como Lefebvre que "o homem só se torna humano criando um mundo humano. É dentro de sua obra e por meio dela que ele se torna ele mesmo, mas sem confundirse com ela, embora não se separe dela" (LEFEBVRE, 2011, p. 46). Fromm também sustenta a tese ao afirmar que "o homem modifica-se no curso da história", pois "ele é produto da história, transformandose na evolução desta". Por isso, "a história é o processo da criação do homem por si mesmo, pela evolução no processo de trabalho das potencialidades que the são dadas ao nascer" (FROMM, 1967, p. 33). Frente a isto, sustentamos que os homens na produção da vida material constroem relações sociais e, nestas relações, as formas da reprodução da vida humano-material. Para que isso possa se materializar, os homens necessitam comer, beber, vestir, ter as condições materiais para viver, pois a premissa básica da vida humana é a existência do homem real humanizado pelo trabalho (AMBONI, 2014, p. 17). Mas para sua existência material, a habilidade para o trabalho deu ao homem um salto ontológico, que é a capacidade de pensar e refletir sobre suas ações do trabalho. Este ato real tornou o homem um ser que fabrica instrumentos de trabalho e, como tal, à medida que a vida social se torna mais complexa, exige do mesmo novas atitudes e novos instrumentos de trabalho. Em primeira instância, o homem vai desenvolvendo um comportamento inteligente. Nesta perspectiva, Alves e Rodrigues sustentam que "além dos instrumentos e técnicas criadas, o homem desenvolveu formas de transmitir às novas gerações o conhecimento daquilo que criava. Eis a origem mais remota da educação" (ALVES; RODRIGUES, 2015, p. 63). O trabalho, portanto, é o elo de mediação entre homem e natureza que pressupõe uma ação que ultrapassa a mera atividade instintiva. É um ato pensado, criador do homem e da sua história. Nestes pressupostos, Braverman escreveu que "o trabalho que ultrapassa a mera atividade instintiva é assim a força que criou a espécie humana e a força pela qual a humanidade criou o mundo como conhecemos" (BRAVERMAN, 1987, p. 83). Antunes também se 
manifesta neste sentido: "sabemos que é a partir do trabalho, em sua realização cotidiana que o ser social se distingue de todas as formas pré-humana. Os homens e mulheres que trabalham são dotados de consciência, uma vez que concebem previamente o desenho e a forma que querem dar ao objeto do seu trabalho" (ANTUNES, 2004, p. 07). Não obstante, Paro argumenta que

Se o que caracteriza o ser humano e o diferencia dos demais seres da natureza é sua nãoindiferença com relação ao mundo, que o leva a criar valores e a fazer deles objetivos que ele busca alcançar, o que lhe possibilita a concretização dessa diferença é precisamente a atividade que ele desenvolve para concretizar esse fim, ou seja, o trabalho humano (PARO, 1999, p. 106).

Estabelecido o pressuposto do trabalho enquanto criador do homem, base ontológica do ser social, é preciso caracterizar o processo de reprodução social, que se dá por meio do trabalho e da educação. Como ser social, o homem necessita do trabalho para manter-se homem, isto é, reproduzir sua condição de homem. Desvinculado da barreira natural pelo trabalho, o homem, enquanto ser social, cria relações de produção e organiza a vida social consoante com o como produzem a existência humano-material. Escreveu Marx e Engels na $A$ Ideologia Alemã que, "esse modo de produção não deve ser considerado meramente sob o aspecto de ser a reprodução da existência física dos indivíduos", pois "ele é, muito mais, uma forma determinada de sua atividade, uma forma determinada de exteriorizar sua vida, um determinado modo de vida desses indivíduos. Tal como os indivíduos exteriorizam sua vida, assim são eles". Com isso, temos que o que os homens "são coincide, pois, com sua produção, tanto com o que produzem como também com o modo como produzem. O que os indivíduos, portanto, depende das condições materiais de sua produção" (MARX; ENGELS, 2007, p. 87). Ou seja, a vida material é determinada pelas condições de produção e os aspectos sociais produtivos de sua reprodução, pois as sociedades estão em permanente movimento.

Neste sentido, podemos inferir que a sociedade se educa para viver em consonância com o como produzem a existência humano-material. Não há um telos em si mesmo, mas uma condição determinada pela forma de estruturação do todo social dominante em qualquer forma de sociedade criada pelo homem. Nesta perspectiva, o trabalho cria o mundo humano e sua reprodução se dá via educação, como elo de humanização constante do ser social. No todo, a unidade trabalho-educação produz e prolonga a existência humana do ser social, pois o homem na forma humana não vive isolado, ele tem necessidade e dependência de outros para sobreviver. A educação também é um processo de sociabilidade, pois é nela que os indivíduos se encontram como sujeitos históricos, com suas histórias de vida e trabalho, de organização social etc. Eles se encontram como criadores da cultura, que vivem uma materialidade real no cotidiano social. Portanto, na produção da vida material do homem há mais do que comer, beber, vestir-se etc., há uma complexa relação social estabelecida, pois a vida social necessita também ser reproduzida como ato contínuo do ser hominizado e, nesta relação complexa, está presente o trabalho como ato educativo a ser reproduzido e ampliado, o que pressupõe também o nascimento de cultura em suas múltiplas dimensões (educacionais, religiosas, políticas etc). Neste caso, elas necessitam do processo educativo como elo de reprodução da cultura do trabalho subsumida ao capital e dos meios ideológicos de sua reprodução.

\section{Educação e trabalho no capitalismo}


A escola atual é uma escola de classe não apenas pela discriminação dos filhos de operários, mas, sobretudo por sua discriminação em relação aos operários. Dizem que sua natureza de classe vai persistir e reforçar-se a despeito da generalização do ensino pós-secundário. E porque a real natureza de classe da escola vem da separação que ela introduz entre 'cultura' e produção, entre ciência e técnica, entre trabalho manual e trabalho intelectual. O capitalismo de hoje de fato não recusa o direito à escola; o que ele recusa é mudar a função social da escola (LET'TIERI, 1996, p. 202).

Trabalho e educação na sociedade burguesa são ideários que se ligam para a reprodução social sob os princípios de Liberdade, Igualdade e Fraternidade, que foram criadas pela Revolução Francesa. O Caráter ideológico está posto, pois a burguesia, enquanto classe social dominante, domina material e culturalmente o trabalho por meio do Estado e das instituições políticas, jurídicas e ideológicas criadas no devir da sociedade burguesa. Na luta ideológica pela escola, os valores da classe dominante se expressam nas formulações pedagógicas. Ponce afirma que “[...] Os ideais pedagógicos não são criações artificiais que um pensador elabora em isolamento e que, depois, procura tornar realidade, por acreditar que elas são justas”. Para ele, são “formulações necessárias das classes que estão empenhadas na luta” e “esses ideais não são capazes de transformar a sociedade, a não ser depois que a classe que os inspirou tenha triunfado e subjugado as classes rivais. A classe que domina materialmente é também a que domina com a sua moral, a sua educação e as suas ideias. Nenhuma reforma pedagógica fundamental pode impor-se antes do triunfo da classe revolucionária que a reclama, e se essa afirmação parece ter sido desmentida algumas vezes pelos fatos, frequentemente, a palavra dos teóricos oculta, conscientemente ou não, as exigências da classe que representa (PONCE, 2000, 169).

Podemos perceber nas análises de Ponce o caráter ideológico da escola como domínio da razão burguesa, cuja centralidade é a subsunção do trabalho ao capital, que se realiza na sociedade e ganha sustentação ideológica na universalização das coisas. Mas a razão Iluminista tem um nome, burguesia; tem um sobrenome, trabalho assalariado e atende pela totalidade de propriedade privada, quer seja na forma material (meios de produção), quer seja na forma animal-hominizado (força de trabalho). Portanto, de criador do homem, o trabalho se transforma em criatura na sociedade capitalista, "o que era uma finalidade central do ser social converte-se em meio de subsistência” (ANTUNES, 2004, p. 08).

$\mathrm{Na}$ construção ideológica do conceito de trabalho pela burguesia, Frigotto afirma que "a concepção burguesa de trabalho vai-se construindo, historicamente, mediante um processo que o reduz a uma coisa, a um objeto, a uma mercadoria que aparece como trabalho abstrato em geral, força de trabalho" e "essa interiorização vai estruturando uma percepção ou representação de trabalho que se iguala à ocupação, emprego, função, tarefa, dentro de um mercado (de trabalho)", diante da qual "perde-se a compreensão, [...] de que o trabalho é uma relação social e que esta relação, na sociedade capitalista, é uma relação de força, de poder e de violência; e, [...] de que o trabalho é a relação social fundamental que define o modo humano de existência", portanto, "não se reduz à atividade de produção material para responder à reprodução físico-biológica (mundo da necessidade), mas envolve as dimensões sociais, estéticas, culturais, artísticas, de lazer etc. (mundo da liberdade)" (FRIGOTTO, 1989, p. 14). Nesta perspectiva, na materialidade do capitalismo, como formação social, o homem, ser social do trabalho, se desvincula de sua 
natureza e seu ser social se apresenta de forma cindida na sociedade, pois o trabalho, como fim de reprodução social se tornou um meio necessário à obtenção dos bens necessários à vida que foi criado pelo modo de produção capitalista e submetido à lógica capitalista pela economia política. Na construção do capitalismo, portanto, o processo de mercantilização da força de trabalho foi escrito com letras indeléveis de sangue, no qual o capital usou das forças públicas do Estado absolutista para conquistar a hegemonia social, subjugando o trabalho real aos ditames da nova ordem social em construção por meio da violência física e da nova moral do trabalho, que foram disseminadas pelas novas religiões - anglicanismo, calvinismo, luteranismo etc - da qual a burguesia soube tirar proveito.

$\mathrm{Na}$ racionalidade da economia política, Adam Smith principia uma análise do processo de criação do capital e traz no interior das discussões a materialidade da escola para os trabalhadores de forma homeopática. Na ótica da classe dominante, a escola atenderia ao processo de trabalho, uma vez que o domínio da linguagem e de conhecimentos específicos mínimos seriam necessária para capacitar a classe trabalhadora à técnica do trabalho. Uma escola para o trabalho, cuja natureza fosse expressão do disciplinamento do corpo e a coação direta ao trabalho. A escola burguesa nasce, portanto, como expressão de classe, mas com uma distinção, a escola no capitalismo, de acordo com Frigotto (1995), é dualista, pois está segmentada na escola que disciplina e adestra os filhos dos trabalhadores e a escola formativa para os filhos da classe dominante.

Este princípio está na base das concepções naturalistas fundamentadas em Desttut de Tracy (século XIX), para quem era natural a existência da escola com formação dualista, na qual uma subordina o ensino à "qualificação das classes trabalhadoras às necessidades imediatas da produção" e a outra o ensino para preparar os quadros dirigentes do Estado, isto é, um ensino para qualificar os filhos das classes dominantes ao domínio do poder para governar a sociedade (FRIGOT'TO, 1995, p. 34). Sua lógica reside na educação de classe para as classes. Nesta linha de análise Ponce sustenta que a educação está centrada na reprodução social, assim ele escreve, "ligada à estrutura econômica das classes sociais, a educação, em cada momento histórico, não pode ser outra coisa a não ser um reflexo necessário e fatal dos interesses e aspirações dessas classes" (PONCE, 2000, p. 169). Isso implica em afirmar que "a educação é o processo mediante o qual as classes dominantes preparam na mentalidade e na conduta das crianças as condições fundamentais da sua própria existência" (PONCE, 2000, 169).

De forma presente e absoluta na vida da sociedade moderna, a escola, criada pela burguesia, cumpre com uma finalidade de domínio cultural e o disciplinamento do corpo para o trabalho, que foi por ela criado. Este princípio se dá por meio do controle social que o Estado exerce sobre a escola por meio dos currículos e a simbologia de regras estabelecidas no interior da escola por horas de estudo e de recreações controladas pelo "apito" disciplinador. Dessa forma, o Estado, via escola, age sobre a formação do sujeito para o trabalho por meio de ações, que Pierre Bourdieu chamou de "violência simbólica", pois desde cedo a criança é submetida a uma aprendizagem da obediência como parte do processo de educaçãoformação à vida social subsumida à sociedade. Disciplinado o trabalho, portanto, é preciso criar o consenso social e balizar as novas relações sociais fundamentada na formação social capitalista. O trabalho continua sendo determinante, mas é preciso atenuar sua importância e força histórica. Isto implica afirmar que o 
trabalho precisa ser "domesticado" de forma contínua para não se tornar uma força centrífuga, capaz de varrer a exploração capitalista sobre o trabalho. Além dos aspectos ideológicos, a educação é o processochave que a burguesia vai criar como elo de consenso e contração do trabalho aos novos ditames sociais, que a sociedade vai assimilando como universal.

Como o Estado burguês nasceu para garantir o direito inalienável à propriedade, ou o direito privado, a educação é uma ferramenta que possibilita a estabilidade do poder burguês transubstanciado no Estado, no qual todas as classes subsomem. Ou seja, a burguesia cria a ilusão de um Estado acima das classes, no qual todos se submetem ao império da lei, pois divide o poder entre executivo, legislativo e judiciário e traz como norma geral uma carta magna (constituição) como elo entre sociedade e Estado. Dessa forma, liderado pela política, o Estado burguês se sustenta por meio da legitimação da ordem pública criada pela ideia de "constituição" ou "contrato social" firmado pelos membros da sociedade. Portanto, é no campo da política que emerge o controle social. Não obstante, Gonçalves afirma que "A política, como a ciência do poder, além de encontrar formas para manter as classes dominantes, também encontra na educação mecanismos para legitimação da ordem por meio da ideologia da classe que são repassadas pelo ensino" (GONÇALVES, 2013, p. 81). Assume assim, a educação como meio de reprodução social, na qual a escola é uma instituição ideológica do Estado. A escola, nesta perspectiva possui uma intencionalidade de classe, que é sua universalização, o que a situa como neutra socialmente. Ao defender a escola para todos, a burguesia cria uma artificialidade ideológica para neutralizar a luta de classes no seu espaço e, com isto, não trazer para seu interior as contradições sociais presentes entre capital e trabalho. A burguesia tenta, com isto, transformar a escola em uma ilha, isolando-a da sociedade, como se fosse uma estrutura à parte, fechada em si mesma. Na análise de Gonçalves, "a educação fica sob a responsabilidade do Estado e este se organiza sob a égide da economia de mercado. Por essa razão o ser humano passa a ser educado para aceitar pacificamente a nova ordem como um fenômeno natural" (GONÇALVES, 2013, p. 84).

Nesta premissa, a organização do trabalho é o elo pelo qual capital e trabalho materializa na produção de mercadorias e, ao mesmo tempo, ocorre a valorização do capital. Ou seja, a sociedade se organiza na reprodução do capital por meio da organização do trabalho, cujo nexo é a captura da subjetividade do trabalho e a extração da mais-valia. Neste processo também está presente a relação trabalho e educação, pois constituem o processo fundante do ser social e seu próprio modo de reprodução social. No capitalismo, sua materialidade é a base social sob a qual a natureza humanizada ainda se constitui como elemento de formação, entretanto o trabalho sofre uma degenerescência, pois a burguesia o transforma em meio para a reprodução da existência da vida do homem, cuja centralidade social é o assalariamento do trabalho.

\section{Conclusão}

Trabalho e educação são sínteses da hominização e reprodução social do homem, tendo na natureza sua fonte primária de trabalho e materialidade da vida do ser social. Ao produzir a existência da vida pelo trabalho, o homem cria as condições para satisfazer outras necessidades, mas o polo central de 
sua existência é o princípio educativo, que se manifestará por meio das atividades de apropriação e transformação da natureza para si, pelo trabalho. Portanto, o ato de comer, beber, vestir-se, se abrigar, proteger-se etc., é um ato realizado pelo homem no seu devir histórico por meio de trabalho. É um ato de materialidade de construção da vida humano-social, pois esta é realizada de forma coletiva. Este salto ontológico funda uma outra característica na sua existência, que é a reprodução e, neste processo, a forma primária de ensinar aos pequenos os meios necessários à vida. Dessa forma, enfatizamos que o nascimento do homem como ser social é um ato de autocriação mediado pelo trabalho. Do trabalho se fez homem e do homem a reprodução social, mas já em outra dimensão, pois a reprodução só é possível tendo em vista o princípio educativo do trabalho.

A reprodução da vida, traz, portanto, o trabalho na sua base ontológica para todas as formações sociais que o homem criou. Este postulado é imanente ao homem que necessita produzir sua vida diuturnamente, pois comer, beber, vestir-se, se proteger, abrigar-se etc., é um ato contínuo à vida do homem, e este processo ele o faz na transformação da natureza pelo trabalho. Na materialidade da vida, o homem cria formações sociais que subverte o sentido da autocriação do homem dado pelo trabalho, no sentido de produzir bens essenciais à vida. No processo social, os homens constroem relações estranhadas entre si, que separam o sujeito do trabalho em classes sociais e, consequentemente, traz o trabalho subordinado à determinada formação social e às relações sociais de produção.

No capitalismo, o trabalho se subsome à formação social na qualidade de trabalho assalariado, mas o aspecto do trabalho fundante do ser social não desaparece. Ele aparece no produto final com valor de uso, mesmo que em última instância, pois toda produção contém um valor imanente ao homem na reprodução diária de existente. A produção de bens com valor de uso só desaparecerá quando o homem não mais houver necessidade de comer, beber, vestir-se, abrigar-se etc., o que implica na extinção do homem, tal qual houve a extinção dos dinossauros.

\section{Referências bibliográficas}

ALVES, Dalton José; RODRIGUES, Alexandre Manuel Esteves. Trabalho, educação e emancipação humana sob a lógica do capital: emancipar de que?. In. Trabalho e emancipação humana. Jundiaí: Paco Editorial, 2015.

AMBONI. Vanderlei. A Escola no Acampamento do MST: Institucionalização e Gestão Estatal da Escola Itinerante Carlos Marighella. Tese de Doutorado. Universidade Federal de São Carlos, São CarlosSP, 2014.

ANTUNES, Ricardo. A dialética do trabalho. São Paulo: Expressão Popular, 2004.

BRAVERMAN, Harry. Trabalho e capital monopolista: a degradação do trabalho no século XX. Rio de Janeiro: Zahar, 1987.

FRIGOTTO, Gaudêncio. A dupla face do trabalho: criação e destruição da vida. In. A Experiência do trabalho e a educação básica. $3^{a}$ ed. Rio de Janeiro: Lamparina, 2010.

FRIGOTTO, Gaudêncio. Educação e a crise do capitalismo real. São Paulo: Cortez, 1995.

FRIGOTTO, Gaudêncio. Meu encontro com Marx e Freud. $4^{a}$ ed. Rio de Janeiro: Zahar, 1967. 
FRIGOTTO, Gaudêncio. Trabalho, conhecimento, consciência e a educação do trabalhador: impasses teóricos e prática. In. Trabalho e Conhecimento: Dilemas na educação do trabalhador. $2^{a}$ Ed. São Paulo: Cortez/Autores Associados, 1989.

FROMM, Erich. Conceito marxista de homem. $2^{\mathrm{a}}$ ed. Rio de Janeiro: Zahar Editores, 1962.

GONÇALVES, Sebastião Rodrigues. Classes sociais, lutas de classes e movimentos sociais. In. Educação e lutas de classes. $2^{\mathrm{a}}$ ed. São Paulo: Expressão Popular, 2013.

LEFEBVRE, Henri. Marxismo. Porto Alegre, RS: L\&PM, 2011.

LETTIERI, A. A fábrica e a escola: crítica da divisão do trabalho. 3. ed. São Paulo: Martins Fontes, 1996.

MARX, Karl; ENGELS, Friedrich. A Ideologia Alemã. São Paulo: Boitempo, 2007.

PARO, Vitor Henrique. Parem de preparar para o trabalho!!! Reflexões acerca dos efeitos do neoliberalismo sobre a gestão e o papel da escola básica. In. Trabalho, formação e currículo: para onde vai a escola? Org. Celso João Ferretti et alii. São Paulo: Xamã. 1999. p. 101-121.

PONCE, Anibal. Educação e luta de classes. 17ª Ed. São Paulo: Cortez, 2000.

SAVIANI, Demerval. Pedagogia histórico-crítica: primeiras aproximações. Campina: Autores Associados, 2003.

\section{Notas:}

${ }^{1}$ Universidade Estadual do Paraná - Campus de Paranavaí. Membro do colegiado de história. Doutor em educação pela UFSCAR. ORCID: Email: vanderlei.amboni@,unespar.edu.br 